\title{
Coal Combustion Wastes Reuse in Low Energy Artificial Aggregates Manufacturing
}

\author{
Claudio Ferone ${ }^{1, *}$, Francesco Colangelo ${ }^{1}$, Francesco Messina ${ }^{1}$, Fabio Iucolano ${ }^{2}$, \\ Barbara Liguori ${ }^{2}$ and Raffaele Cioffi ${ }^{1}$
}

1 INSTM Research Group Naples Parthenope, Department of Engineering, Parthenope University of Naples, Centro Direzionale Naples, Isola C4, Naples 80143, Italy;

E-Mails: francesco.colangelo@uniparthenope.it (F.C.); francesco.messina @uniparthenope.it (F.M.); raffaele.cioffi@uniparthenope.it (R.C.)

2 Department of Chemical, Materials and Production Engineering, University of Naples Federico II, Piazzale Tecchio, 80, Naples 80125, Italy; E-Mails: fabio.iucolano@ unina.it (F.I.); barbara.liguori@unina.it (B.L.)

* Author to whom correspondence should be addressed: E-Mail: claudio.ferone @ uniparthenope.it; Tel.: +39-081-547-6713; Fax: +39-081-547-6777.

Received: 17 July 2013; in revised form: 20 October 2013 / Accepted: 23 October 2013 /

Published: 31 October 2013

\begin{abstract}
Sustainable building material design relies mostly on energy saving processes, decrease of raw materials consumption, and increase of waste and by-products recycling. Natural and lightweight artificial aggregates production implies relevant environmental impact. This paper addresses both the issues of residues recycling and energy optimization. Particularly, three coal combustion wastes (Weathered Fly Ash, WFA; Wastewater Treatment Sludge, WTS; Desulfurization Device Sludge, DDS) supplied by the Italian electric utility company (ENEL) have been employed in the manufacture of cold bonded artificial aggregates. Previously, the residues have been characterized in terms of chemical and mineralogical compositions, water content, particle size distribution, and heavy metal release behavior. These wastes have been used in the mix design of binding systems with the only addition of lime. Finally, the artificial aggregates have been submitted to physical, mechanical, and leaching testing, revealing that they are potentially suitable for many civil engineering applications.
\end{abstract}

Keywords: sustainable concrete and mortars; artificial aggregates; weathered coal fly ash; wastewater treatment sludge; desulfurization device sludge 


\section{Introduction}

\subsection{Research Significance}

Many authors have already discussed the environmental impact of building material industry [1-3]. In this context, concrete and cementitious composites found a field of tremendous growth, so that, nowadays, concrete is the most used material throughout the world. The analysis of environmental issues associated with the construction industry must be carried out, considering just one final application because every material has particular production process parameters (raw materials supplying/processing, casting/curing conditions, etc.). When the whole engineering application is defined, the user can assess what is the design strategy that has to be followed in order to increase the sustainability. Generally, the designer/analyst will act on one or more of the following issues:

1. Energy saving in production processes;

2. Decrease of natural raw materials consumption;

3. Recycling of wastes/by-products of other industrial processes.

In cementitious binding systems, excluding chemical admixtures, it is possible to find different components, depending on the particular structural aim of the design (reinforced concrete for residential buildings, precast concrete for bridges, concrete for pavements, rendering mortars, etc.). A brief review is reported in Figure 1.

Figure 1. Components of cementitious composites in a sustainable design scheme.

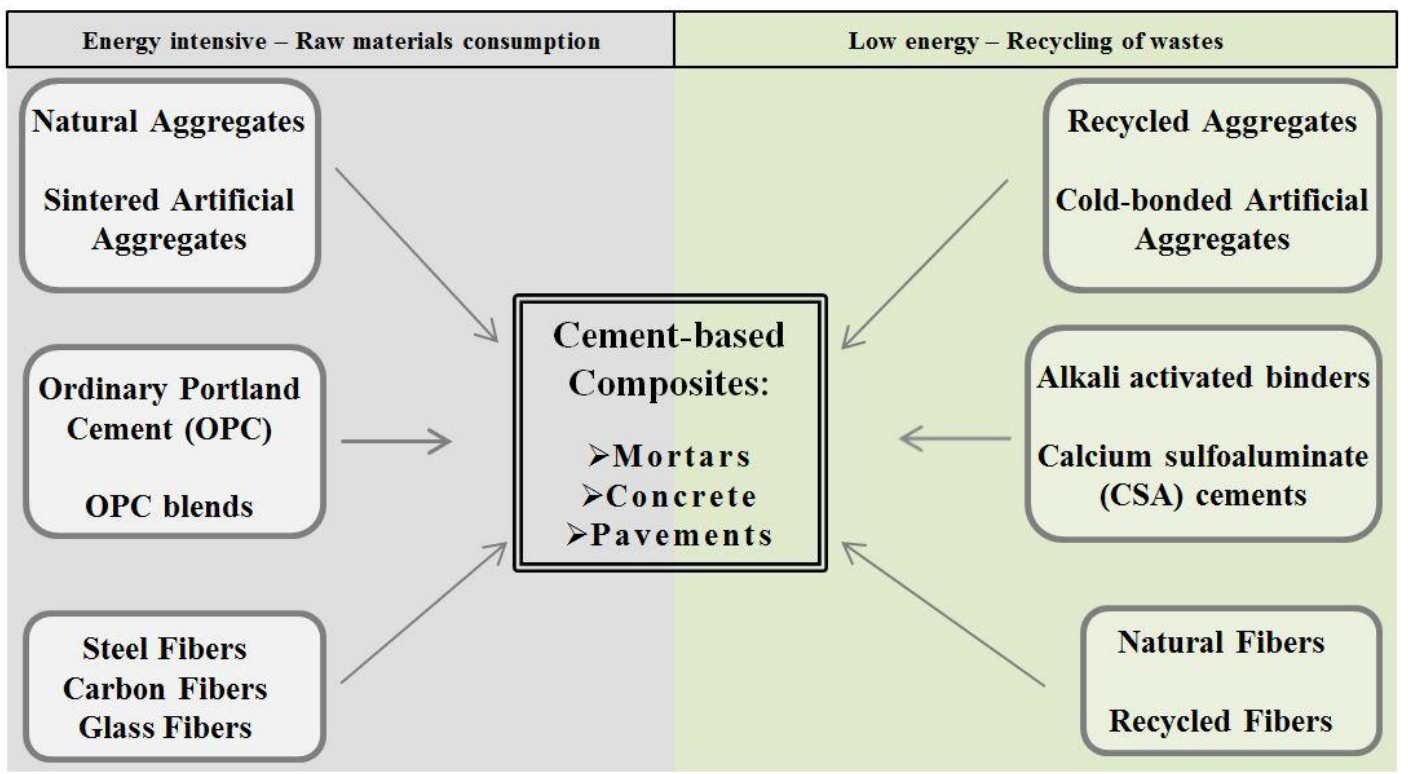

In Figure 1 it is possible to distinguish three different lines of action for the sustainable design practice, each one corresponding to a component of the composite: (1) aggregates, both natural and artificial; (2) binding systems, which are extremely variable depending on the application; and (3) fibers, not always employed, which are used in fiber reinforced concrete, mortars, etc. Furthermore, two opposite sides (the first one in grey, the second one in green) collect environmentally hostile and friendly options for materials design in civil engineering. Even if sustainability is a broader concept, 
also contemplating social and economic issues, the above-described approach can help designers/analysts in the initial phases of a project, where few variables can be taken into account, depending above all on the construction site/area. In the first action line (aggregates), the introduction in the market of recycled and artificial cold bonded aggregates is highly desirable, both for natural resources depletion reduction, and wastes reuse, with potential market in structural and environmental technologies [4-11]. In the second one (binding systems), ordinary Portland cement (OPC) and OPC blends still play a key role. Greener options are, thus, needed in order to reduce the environmental issues related to relevant amounts of $\mathrm{CO}_{2}$ release in the atmosphere by the clinker synthesis process. Even if few real applications can be found, a huge number of experimental studies are available in literature. Developed at the end of the last century, calcium sulfoaluminate (CSA) cements represent one of the first attempts in the reduction of clinker impact on the environment [12,13]. More recently, research attention on alkali activated binders is relevantly increased, frequently presented as a green alternative to traditional cements, both for low process and curing temperatures and for the possibility of employing wastes/by-products/sludge as raw aluminosilicate powdered precursor [14-19]. This new class of materials has been widely tested for several civil and environmental engineering applications, but there is still a lack of data on the behavior of these materials under service life conditions [20-26]. In the case of fiber reinforcements (action line 3) able to give composites with improved physico-mechanical performances, natural and recycled fibers are of great interest $[27,28]$.

This paper focuses on the possibility of employing coal combustion wastes in a cold bonding pelletization process in order to produce sustainable artificial aggregates, developing, thus, a possible alternative in the above described action line 2. The possibility of employing residues with binding capability or filler physical properties is typical of a cold bonding pelletization process $[11,13,16,17]$. In fact, in order to obtain aggregates with sufficient mechanical properties, both binding and filler agents are needed. The environmental benefits of this process do not rely just on materials recycling, but also on the very low temperature at which the granulation is carried out. In fact, the cold bonding pelletization is usually carried out at room temperature.

\subsection{Coal Combustion Residues Environmental Issues and Recycling Strategy}

Coal fired power plants are still one of the main electrical energy sources throughout the world. Despite new designs, they are responsible of relevant greenhouse gases emissions, contributing to both air pollution and acid rain [29].

According to the Italian electric utility company (ENEL, Rome, Italy, [30], in 2012, forty-three thermoelectric power plants are operating in Italy, with a net power, which can be estimated to be about 24,723 MW. Many different fossil fuel resources are used and, particularly, coal represents the first one, covering $75.41 \%$ of the needs. These combustion-based energy production processes generate many industrial outputs. First of all, the total amount of equivalent $\mathrm{CO}_{2}$ is equal to about $38 \times 10^{6} \mathrm{t}$. Furthermore, both liquid and solid residues are produced. Wastewater quantity estimation is about $6 \times 10^{6} \mathrm{~m}^{3}$ and approximately $88 \%$ of this is reused inside the plants. As far as solid wastes are concerned, about $2.3 \times 10^{6} \mathrm{t}$ of special wastes have been produced in 2012 , and $80 \%$ of these have been recycled. Particularly, $99 \%$ of the special wastes is made of non-hazardous wastes. The specific production of coal combustion residues is reported in Figure 2 [30]. 
Figure 2. Coal combustion residues amounts production and recycling in Italy in 2012 (adapted with permission from ENEL Environmental Report, 2012 [30]. Copyright by the National Agency for Electric Energy, ENEL).

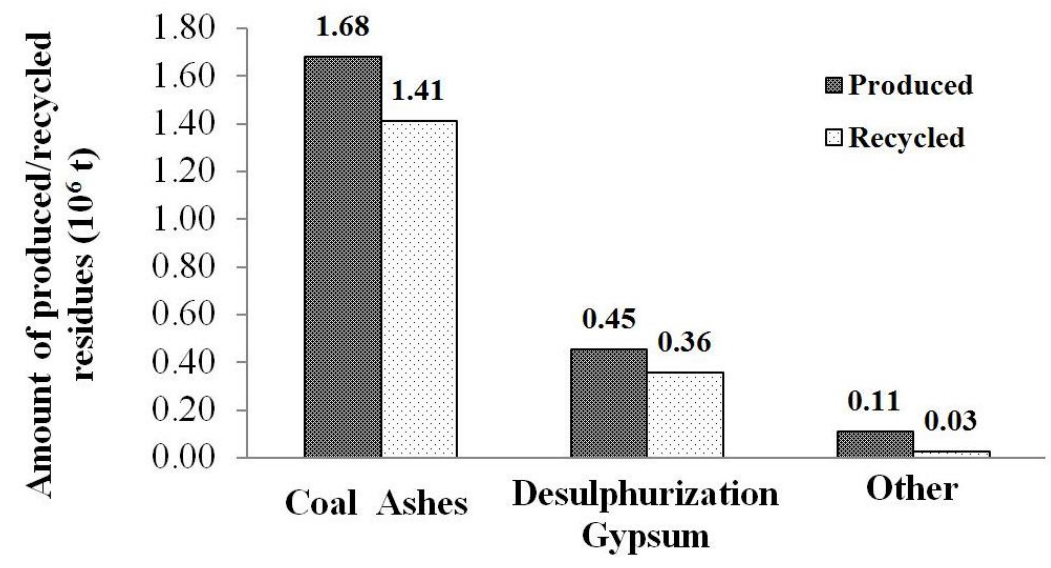

The major impacts of coal combustion solid residues disposal on terrestrial ecosystems include mostly the leaching of potentially toxic substances into soils and groundwater and several potential attacks to vegetation (reductions in plant establishment and growth; changes in the elemental composition of vegetation; increased mobility and accumulation of potentially toxic elements throughout the food chain) [29].

This study deals with a recycling strategy of coal combustion residues for building materials industry. Particularly, three residues coming from Brindisi (Italy) ENEL power plants have been considered: Weathered Fly Ash (WFA), Wastewater Treatment Sludge (WTS), and Desulfurization Device Sludge (DDS). These residues have been previously characterized in terms of physical and chemical properties. In the second phase of experimental program mixtures of the artificial aggregates have been designed and the setting of the cold bonding process has been fixed. In the last phase, the produced artificial aggregates have been submitted to physical and mechanical testing. The heavy metals leaching behavior of the cementitious mixtures have been also evaluated.

The cold bonded aggregates exhibited good physical and mechanical properties, and the WFA/lime binding matrix showed a relevant capability to stabilize heavy metals.

\section{Experimental Program}

\subsection{Coal Combustion Residues Physical and Chemical Characterization}

WFA stands for fly ash coming from wet storage, without drying. In this case, fly ash comes from a temporary storage basin of an ENEL coal-fired power plant, located in Brindisi (Italy). The ash is periodically sprinkled with water and so resulting waste is of a moist consistency with water content much lower than that would be given by pond storage. This waste must be distinguished from rejected fly ash, a low-grade fly ash, which is not used in blended cements due to its high carbon content and particle size mostly higher than $75 \mu \mathrm{m}$ [31]. Particle size distribution of WFA has been determined by means of a Malvern Instrument Mastersizer 2000 laser scattering analyzer (Worcestershire, UK, particles observation range: $0.02 \div 2000 \mu \mathrm{m}$ ), after that the ash has been dried in an oven at $105{ }^{\circ} \mathrm{C}$, without grinding operations. For coarse samples, namely WTS and DDS, particle size analysis has 
been carried out by means of mechanical sieving, according to the UNI EN 933-1 and UNI EN 933-2 standards [32,33]. After this, the two wastes have been grinded using a $\operatorname{Retsch}^{\circledR}$ DM 200 disc mill (Haan, Germany, material feed size $<20 \mathrm{~mm}$, final fineness $<100 \mu \mathrm{m}$ ).

Water content of the residues has been obtained after drying the samples in an oven at $105{ }^{\circ} \mathrm{C}$ in the case of WFA, and $60{ }^{\circ} \mathrm{C}$ in the other cases. Loss on ignition (LOI) has been determined by thermal heating up to $1050{ }^{\circ} \mathrm{C}$. The three wastes have been submitted to total acid digestion (ASTM 5258-92) [34] and subsequent chemical analysis through inductively coupled plasma atomic emission spectrometry (ICP-AES) technique for the determination of metals content. The mineralogical analysis (X-ray diffraction analysis, XRD) has been performed by means of a Philips PW 1730 diffractometer (Amsterdam, the Netherlands, $\mathrm{Cu} \mathrm{K} \alpha$ radiation, $2 \theta=5^{\circ}-60^{\circ}$, step width $2 \theta=0.02^{\circ}$ and $1 \mathrm{~s}$ data collection per step).Thermal analysis has been carried out by means of thermogravimetric analysis (TGA), making use of a TA Instruments thermal analyser SDT2960 (New Castle, USA) (weight of the sample: $10 \mathrm{mg}$; heating rate: $10^{\circ} \mathrm{C} \cdot \mathrm{min}^{-1}$; atmosphere: air).Finally, the residues have been submitted to UNI EN 12457-2 [35] leaching test. This is a static test that makes use of deionized water as leachant in a $10 \mathrm{~L} \cdot \mathrm{kg}^{-1}$ liquid to solid ratio. Its duration, in the case of granular solids (size $<3 \mathrm{~mm}$ ), must be 24 $\mathrm{h}$. To prevent metals precipitation after leaching, the leachate $\mathrm{pH}$ must be brought to 2 by means of $1 \mathrm{~N}$ $\mathrm{HNO}_{3}$ solution.

\subsection{Artificial Aggregates Production and Testing}

The manufacture of cold bonded aggregates has been carried out by means of a laboratory-scale pelletization apparatus. Process parameters have been chosen on the basis of previous observations, which can be found in literature [11,13,16,17]. The pelletization apparatus is equipped with an $80 \mathrm{~cm}$ diameter rotating disk whose tilting angle has been fixed at $50^{\circ}$. The revolution speed was fixed at $45 \mathrm{rpm}$. The powders have been previously mixed with water by means of a Hobart mixer and then slowly and continuously poured onto the disk. The water to solid ratio has been adjusted during the production process using a nozzle to spray more water into the mixes. Mix design of aggregates is reported in Table 1. In all designed mixtures an amount of lime ranging from $10 \%$ to $40 \%$ has been added to the wastes. The set of compositions is essentially made of three subcategories. The first one is represented by $\mathrm{C}_{x}$ mixtures, where $x$ is the WFA content (wt. \%). Among these three mixtures, the reference is $\mathrm{C}_{60}$ where the WFA/L ratio is fixed at 3:2 in order to obtain the maximum amount of cementitious hydration products, on the basis of the well-known activating capability of $\mathrm{Ca}(\mathrm{OH})_{2}$. The other two mixes $\left(\mathrm{C}_{80}\right.$ and $\left.\mathrm{C}_{90}\right)$ have been studied to maximize the amount of reused waste. The second subcategory of compositions is the $\mathrm{C}_{x} \mathrm{~W}_{y}$ one, where $\mathrm{x}$ is again WFA content, while $\mathrm{y}$ stands for WTS content. $\mathrm{C}_{30} \mathrm{~W}_{50}$ and $\mathrm{C}_{24} \mathrm{~W}_{60}$ compositions represent trials to reuse WTS in a $\mathrm{C}-\mathrm{S}-\mathrm{H}$ matrix obtained by keeping WFA/L ratio at 3:2. A narrow range of WTS content has been chosen because of the decay of the physico-mechanical performance, due to the unreactive nature of this waste. On the other side a low amount of waste would reduce the benefit of the recovery process. Finally, the $C_{x} D_{y}$ compositions have been designed on the basis of previous experience [36], where a tuff-lime-gypsum system was studied. WFA:L:DDS reference ratio has been fixed at 4:3:3 because, according to the above mentioned study, this mixture is theoretically able to give the conversion of $35 \%$ of silica into $\mathrm{C}-\mathrm{S}-\mathrm{H}$ and $70 \%$ alumina into ettringite. 
Curing conditions have been chosen in order to obtain sufficient mechanical performance without increasing the energy consumption of the process. For this reason, artificial aggregates were cured for 56 days at room temperature and $100 \% \mathrm{RH}$, and experimental results were simultaneously compared to those obtained by curing the specimens at $40{ }^{\circ} \mathrm{C}$ for the first three days. At the end of the curing phase the grain size distribution of the hardened products has been determined by sieving, according to [32].

Table 1. Artificial aggregates compositions, wt \%.

\begin{tabular}{cccccc}
\hline Mixtures & WFA & L & DDS & WTS & W/S ratio \\
\hline $\mathrm{C}_{90}$ & 90 & 10 & - & - & 0.22 \\
$\mathrm{C}_{80}$ & 80 & 20 & - & - & 0.25 \\
$\mathrm{C}_{60}$ & 60 & 40 & - & - & 0.29 \\
$\mathrm{C}_{30} \mathrm{~W}_{50}$ & 30 & 20 & - & 50 & 0.25 \\
$\mathrm{C}_{24} \mathrm{~W}_{60}$ & 24 & 16 & - & 60 & 0.30 \\
$\mathrm{C}_{40} \mathrm{D}_{30}$ & 40 & 30 & 30 & - & 0.25 \\
$\mathrm{C}_{25} \mathrm{D}_{10}$ & 25 & 15 & 10 & 50 & 0.28 \\
$\mathrm{C}_{20} \mathrm{D}_{15}$ & 20 & 15 & 15 & 50 & 0.31 \\
\hline
\end{tabular}

In order to evaluate hydration kinetics of the most complex system, which is represented by $\mathrm{C}_{x} \mathrm{D}_{y}$, differential thermal analysis (DTA) has been performed on $\mathrm{C}_{40} \mathrm{D}_{30}$ where WTS has not been employed. This analysis has been carried out on samples cured at room temperature and after $40{ }^{\circ} \mathrm{C}$ curing. The instrument used for this test was the same used for residues characterization.

Successively, the artificial aggregates have been submitted to the following tests: dry density and water absorption capacity, crushing strength, and Los Angeles coefficient. Water absorption was determined according to the UNI EN 1097-6 standard [37]. Samples were first dried in the oven at $110 \pm 5{ }^{\circ} \mathrm{C}$ until constant mass. The measured values of dry mass $\left(m_{\mathrm{d}}\right)$ and saturated surface-dry mass $\left(m_{\mathrm{ssd}}\right)$ after $24 \mathrm{~h}$ immersion were used in the calculation of water absorption (WA):

$$
\mathrm{WA}=\frac{m_{\mathrm{ssd}}-m_{\mathrm{d}}}{m_{\mathrm{d}}} 100
$$

Crushing tests were performed, according to the UNI EN 13055-1 standard [38], in order to determine aggregates engineering properties. The aggregates were placed in a steel cylinder and compacted by means of mechanical vibration. After that, samples were charged through a steel piston by means of a CONTROLS ${ }^{\circledR}$ 50-C56Z00 compression testing machine [Cernusco (MI), Italy] with a capacity of $3000 \mathrm{kN}$. The test method for the Los Angeles Coefficient involves a test aggregate sample with particles between $10 \mathrm{~mm}$ and $14 \mathrm{~mm}$ in size. The sample is rotated in a steel drum with a specified quantity of steel balls, at a speed of 31 to 33 revolutions per minute for 500 revolutions. The Los Angeles Coefficient is calculated from the proportion of the sample reduced to less than $1.6 \mathrm{~mm}$ in size.

After physical and mechanical characterization, leaching tests have been carried out on artificial aggregates. The aggregates have been submitted to leaching test for monolithic material according to [35], carried out with leachant renewals at 2 and $18 \mathrm{~h}$ and a total duration of $48 \mathrm{~h}$ ensuring a liquid volume/solid surface ratio of $10 \mathrm{~cm}$. As in the granular material case, the $\mathrm{pH}$ must be brought to 2 by means of $1 \mathrm{M} \mathrm{HNO}_{3}$ before the metals released are analyzed. For environmentally critical systems, the cumulative leaching data after 72, 336 and $672 \mathrm{~h}$ have been determined. 


\section{Experimental Results and Discussion}

\subsection{Physico-Chemical Characterization of Residues}

In Figure 3, particle size distributions of the three residues are reported. As far as the chemical composition is of concern, the three residues exhibit a high heterogeneity, as can be observed in Table 2 .

DDS shows the highest water content and the maximum LOI. In the case of WFA, the high water content is related to the storage method.

Figure 3. Particle size distributions of weathered coal fly ash, wastewater treatment sludge and desulfurization device sludge.

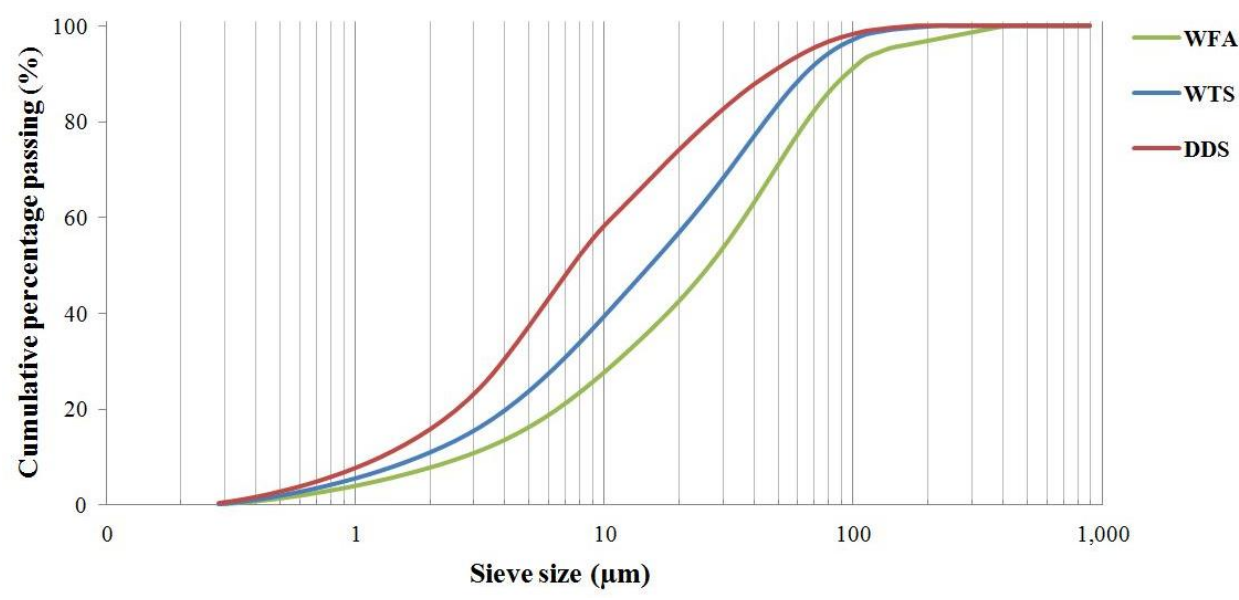

Table 2. Waste samples chemical compositions, wt \%.

\begin{tabular}{ccccccccccccc}
\hline Analyte & $\mathbf{A l}_{2} \mathbf{O}_{\mathbf{3}}$ & $\mathbf{N a}_{2} \mathbf{O}$ & $\mathbf{K}_{\mathbf{2}} \mathbf{O}$ & $\mathbf{S O}_{\mathbf{3}}$ & $\mathbf{C a O}$ & $\mathbf{F e}_{2} \mathbf{O}_{3}$ & $\mathbf{M g O}$ & $\mathbf{M n O}$ & $\mathbf{P}_{2} \mathbf{O}_{5}$ & $\mathbf{T i O}_{2}$ & $\mathbf{S i O}_{2}$ & $\mathbf{L O I}$ \\
\hline WFA & 28.10 & 0.87 & 1.89 & 0.08 & 4.32 & 6.99 & 1.59 & 0.06 & 1.12 & 0.04 & 53.71 & 6.0 \\
WTS & 6.43 & 0.52 & 0.17 & 2.74 & 32.70 & 19.70 & 7.01 & 0.10 & 0.29 & 0.31 & 7.50 & 34.5 \\
DDS & 4.60 & 1.33 & 0.26 & 38.80 & 22.30 & 1.00 & 1.97 & 0.03 & 0.28 & 0.20 & 12.05 & 11.1 \\
\hline
\end{tabular}

It is well known that coal fly ashes are essentially aluminosilicates which can behave as pozzolanic material, and so be able to substitute partially Portland cement. On the other hand, WTS main chemical components are calcium and iron oxides, with quite relevant amounts of $\mathrm{SiO}_{2}, \mathrm{MgO}, \mathrm{Al}_{2} \mathrm{O}_{3}$, and $\mathrm{SO}_{3}$. Finally, DDS is characterized by the maximum content of $\mathrm{SO}_{3}$ among the wastes here studied. Apart from this, significant quantities of $\mathrm{CaO}, \mathrm{SiO}_{2}$, and $\mathrm{Al}_{2} \mathrm{O}_{3}$ can be observed. In Table 3, the amount of heavy metals in the three wastes can be found, showing that the highest environmental risk is related to WTS.

Table 3. Heavy metals content in wastes samples, ppm.

\begin{tabular}{ccccccccc}
\hline Analyte & $\mathbf{C d}$ & $\mathbf{C r}$ & $\mathbf{C u}$ & $\mathbf{N i}$ & $\mathbf{P b}$ & $\mathbf{S e}$ & $\mathbf{V}$ & $\mathbf{Z n}$ \\
\hline WFA & 10 & 40 & 30 & 50 & 20 & 10 & 110 & 50 \\
WTS & 10 & 60 & 100 & 80 & 10 & 10 & 160 & 1390 \\
DDS & 10 & 20 & 10 & 20 & 10 & 10 & 50 & 10 \\
\hline
\end{tabular}


The results reported in Table 2 are in agreement with XRD and thermal analysis, which are reported in Figures 4 and 5, respectively. WFA (green curve in Figure 4) is highly amorphous with the presence of a small amount of Quartz and Mullite. The WTS (blue in Figure 4) sample is mainly composed of calcite, while DDS (red in Figure 4) shows calcium sulfate hemihydrate and calcite peaks.

Figure 4. XRD analysis results for the three coal combustion residues $(\mathrm{C}=$ Calcite; $\mathrm{M}=$ Mullite; $\mathrm{Q}=$ Quartz; and $\mathrm{G}=$ Gypsum).

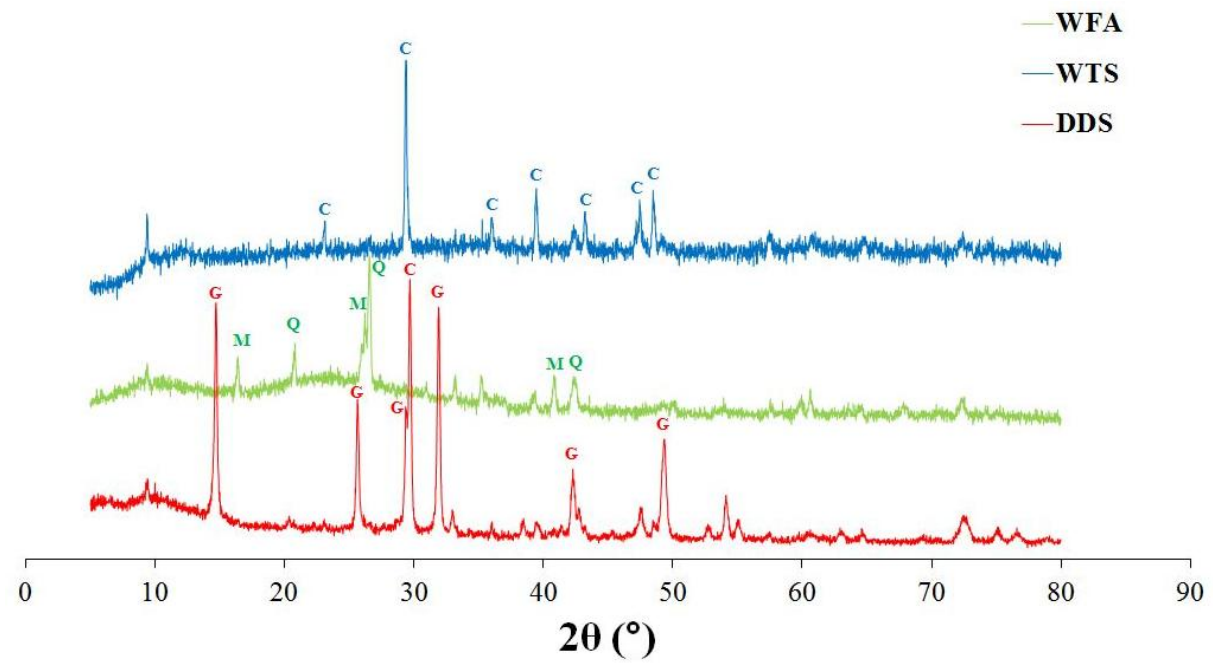

Gravimetric thermal analysis, reported in Figure 5, confirms the results of XRD analysis in terms of identified phases. Observing the WFA curve, the range from $500{ }^{\circ} \mathrm{C}$ to $700{ }^{\circ} \mathrm{C}$ can be related to combustion of unburnt carbon in coal fly ash. As far as WTS curve, iron hydroxides decomposition between about $200{ }^{\circ} \mathrm{C}$ and $500{ }^{\circ} \mathrm{C}$ can be observed. For DDS, it can be argued that calcium sulfate hydrate decomposes in the range between about $100{ }^{\circ} \mathrm{C}$ and $150{ }^{\circ} \mathrm{C}$. Considering both the WTS and DDS curves, in the range between about $700{ }^{\circ} \mathrm{C}$ and $800{ }^{\circ} \mathrm{C}$ the carbonates decomposition occurs with $\mathrm{CO}_{2}$ loss. The overall weight loss is $5 \%, 30 \%$, and $8 \%$, for the samples WFA, WTS, and DDS, respectively.

Figure 5. Thermal analysis results for the three coal combustion residues.

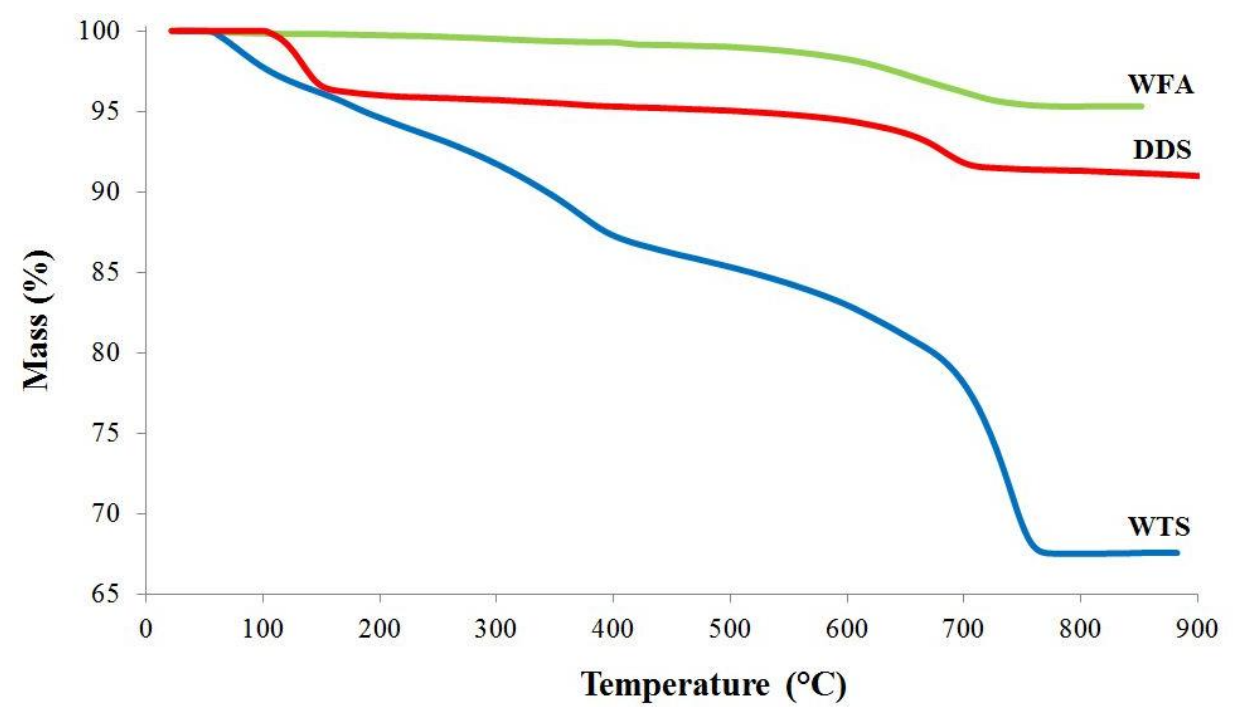


The leaching behavior of WFA, DDS, and WTS, for which few results can be found in literature [39], has been analyzed to evaluate the potential environmental issues related to the recycling of coal combustion wastes in artificial aggregates manufacturing. The release results are reported in Table 4. According to Italian regulation on simplified recovery procedure for non-hazardous wastes [40], the results obtained by applying the leaching test [35] must be compared to the concentration limits reported in Table 4. Particularly, the comparison must be carried out considering the release at three days. It can be observed that only Ni content poses a management issue, even if a few other metal $(\mathrm{Cr}$, $\mathrm{Cu}, \mathrm{Se})$ contents are just below the limits. In the next section the leaching behavior on monolithic product will be evaluated, to ensure that also these small excesses of released metals will be immobilized by the cementitious binder systems.

Table 4. Metals release of samples: Weathered Fly Ash (WFA), Wastewater Treatment Sludge (WTS) and Desulfurization Device Sludge (DDS), $\mu \mathrm{g} / \mathrm{L}$.

\begin{tabular}{ccccccccc}
\hline Analyte & $\mathbf{C d}$ & $\mathbf{C r}$ & $\mathbf{C u}$ & $\mathbf{N i}$ & $\mathbf{P b}$ & $\mathbf{S e}$ & $\mathbf{V}$ & $\mathbf{Z n}$ \\
\hline WFA & 0.04 & 8.37 & 13.15 & 13.71 & 0.31 & 1.23 & 0.35 & 0.67 \\
WTS & 0.10 & 26.22 & 34.76 & 74.38 & 0.12 & 7.10 & 0.01 & 3.51 \\
DDS & 0.57 & 4.37 & 7.67 & 10.98 & 0.23 & 4.37 & 12.25 & 2.15 \\
Limits * & 5 & 50 & 50 & 10 & 50 & 10 & 250 & 3000 \\
\hline \multicolumn{7}{c}{ * Ministerial Decree 5/4/2006 n. 186 [40]. }
\end{tabular}

\subsection{Physical, Mechanical Properties, and Heavy Metals Release of Artificial Aggregates}

The physical and mechanical properties of the cold bonded aggregates are influenced by both process and curing parameters and by raw materials hydration kinetics. In fact, as already pointed out in literature $[36,41,42]$, the presence of chemical gypsum must be analyzed because the sulfate phases could give rise to ettringite formations. Thus, considering the simultaneous presence of a pozzolanic materials such as coal fly ash, a final heterogeneous hydration product containing both ettringite and calcium silicate hydrate $(\mathrm{C}-\mathrm{S}-\mathrm{H})$ could be generated. In order to assess this particular hydration behavior, both chemical and thermal analyses have been carried out.

Figure 6 shows the two thermograms (curves a and b), obtained for the system $\mathrm{C}_{40} \mathrm{D}_{30}$ cured at $40{ }^{\circ} \mathrm{C}$ for 7 and 28 days, respectively. It can be seen that the endothermic effects, due to the decomposition of neo-formed hydrated phases, calcium silicate hydrate $(\mathrm{C}-\mathrm{S}-\mathrm{H})$, and ettringite, and those due to the decomposition of unreacted gypsum and calcium hydroxide can be observed. Specifically, the endothermic peaks at $95 \pm 25{ }^{\circ} \mathrm{C}, 125 \pm 20{ }^{\circ} \mathrm{C}, 175 \pm 15{ }^{\circ} \mathrm{C}$ and $495 \pm 10{ }^{\circ} \mathrm{C}$ can be associated to $\mathrm{C}-\mathrm{S}-\mathrm{H}$, ettringite, gypsum, and calcium hydroxide, respectively $[36,41,42]$. A very good conversion of raw materials towards ettringite can be detected in curve $b$, where the calcium hydroxide peak is widely reduced and the gypsum effect is almost completely included in the ettringite one. In this curve, a shoulder associated to the $\mathrm{C}-\mathrm{S}-\mathrm{H}$ formation is also present. The thermal effects shown in curve a of Figure 7 show that, at room temperature, hydration reactions happen more moderately. In fact, the presence of a higher amount of unreacted calcium hydroxide and gypsum is clearly evident.

The last results are confirmed by the XRD patterns for $\mathrm{C}_{40} \mathrm{D}_{30}$ system cured for 28 days at $40{ }^{\circ} \mathrm{C}$ (data not shown) for which the main crystalline phases observed are ettringite, gypsum, calcium 
hydroxide, mullite, and quartz. The other systems containing DDS, showed qualitatively similar behavior but, due to the differences in composition, the areas of endothermic peak were lower.

Figure 6. Thermal analysis results for the system $\mathrm{C}_{40} \mathrm{D}_{30}$ cured at $40{ }^{\circ} \mathrm{C}$ for (a) 7 days; and (b) 28 days.

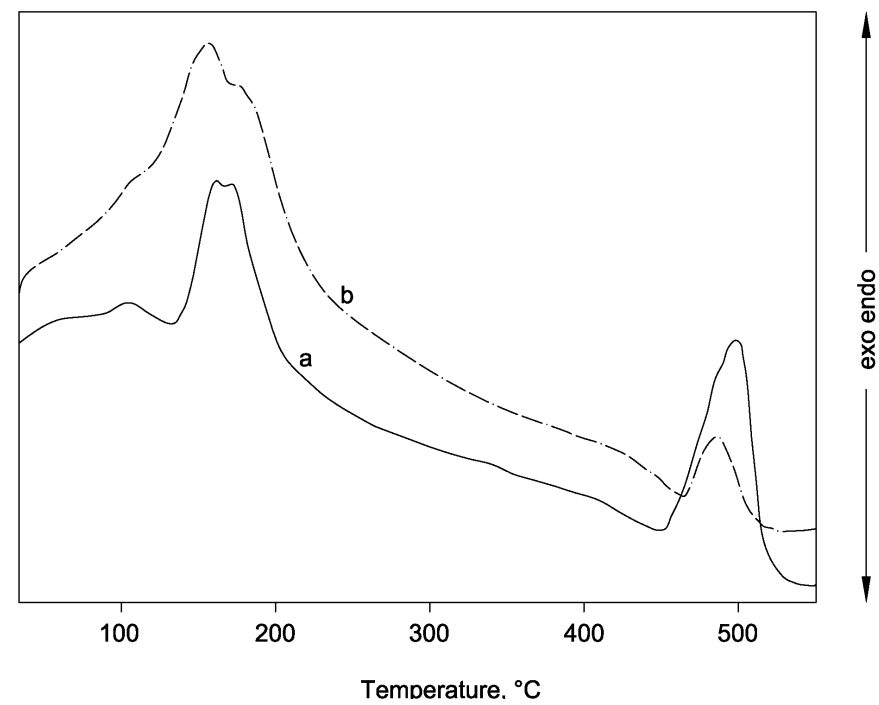

The complete set of above results confirm that binder mixtures containing two wastes, such as weathered coal fly ash and chemical gypsum, and calcium hydroxide can give hydrated system based on ettringite and calcium silicate hydrate. Furthermore, the same type of coal fly ash shows a good reactivity towards lime. This is in agreement with previous studies where aluminosilicates of higher quality were mixed with natural and chemical gypsum and lime [36,41,42].

Figure 7. Thermal analysis results for the system $\mathrm{C}_{40} \mathrm{D}_{30}$ cured at room temperature for (a) 7 days; and (b) 28 days.

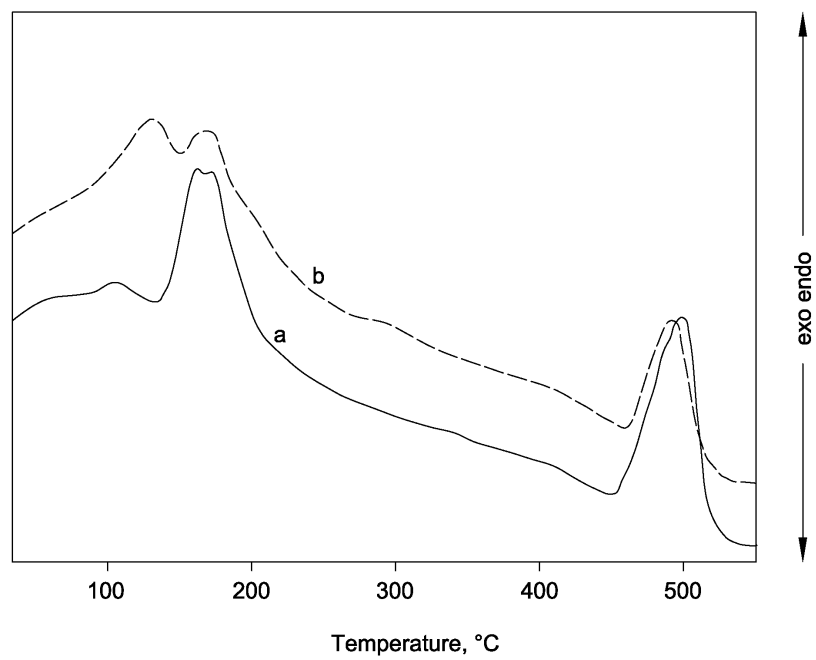

By means of the pelletization process, $6 \div 18 \mathrm{~mm}$ size aggregates have been obtained. In Figures 8 and 9 the results of physical characterization are reported in terms of dry density and water absorption capacity. According to [38], the artificial aggregates can be classified as lightweight as dry density values are always lower than $2000 \mathrm{~kg} / \mathrm{m}^{3}$. Aggregates containing DDS show an average dry 
density, which is about $20 \%$ lower than other ones. Particularly, $\mathrm{C}_{60}$ and $\mathrm{C}_{30} \mathrm{~W}_{50}$ show the highest density for $40{ }^{\circ} \mathrm{C}$ and room temperature curing, respectively.

Absorption properties follow the overall trend of density for the various designed compositions. In fact, $\mathrm{C}_{40} \mathrm{D}_{30}$ aggregates, which do not show a very dense structure, behave as highly porous and reach the highest value of water absorption capacity (WAC). The WAC of all the hardened mixtures ranges from $15 \%$ to $20 \%$, revealing to be quite similar to commercial lightweight aggregates.

Crushing strength values are reported in Figure 10. These values are quite heterogeneous, except for the two mixtures that have been designed on a theoretical basis (i.e., $\mathrm{C}_{60}$ and $\mathrm{C}_{40} \mathrm{D}_{30}$ ) rather than on economical and management considerations. In fact, going from $\mathrm{C}_{90}$ to $\mathrm{C}_{60}$, strength increases more than $100 \% . \mathrm{C}_{60}$ mixture is designed with WFA/L ratio fixed at $3: 2$, while for $\mathrm{C}_{80}$ and $\mathrm{C}_{90}$ is $1: 4$ and $1: 9$, respectively.

Figure 8. Dry density of artificial aggregates.

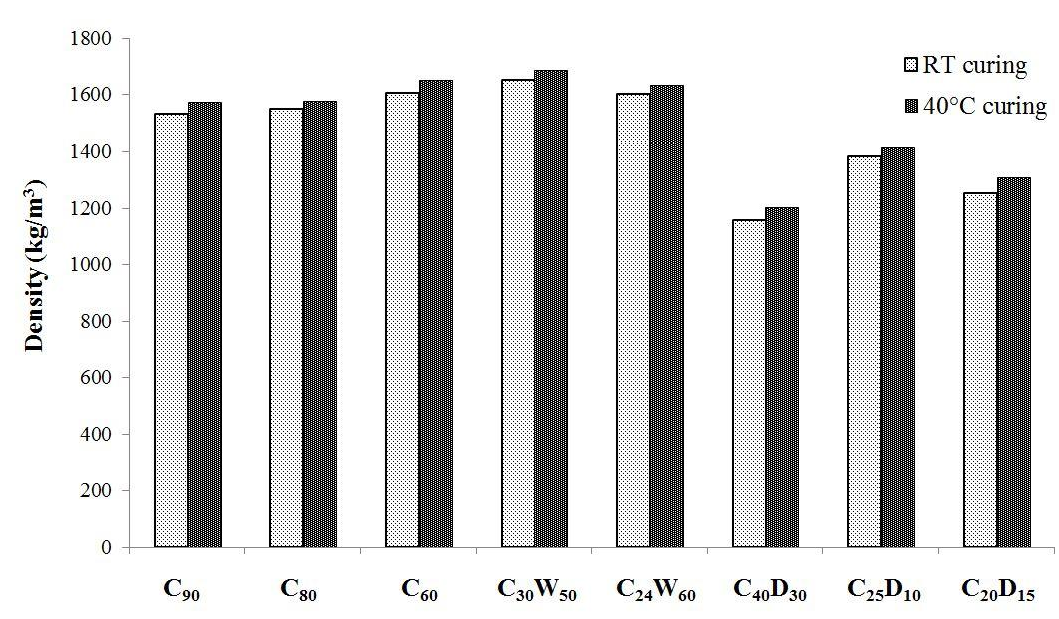

Figure 9. Water absorption capacity of artificial aggregates.

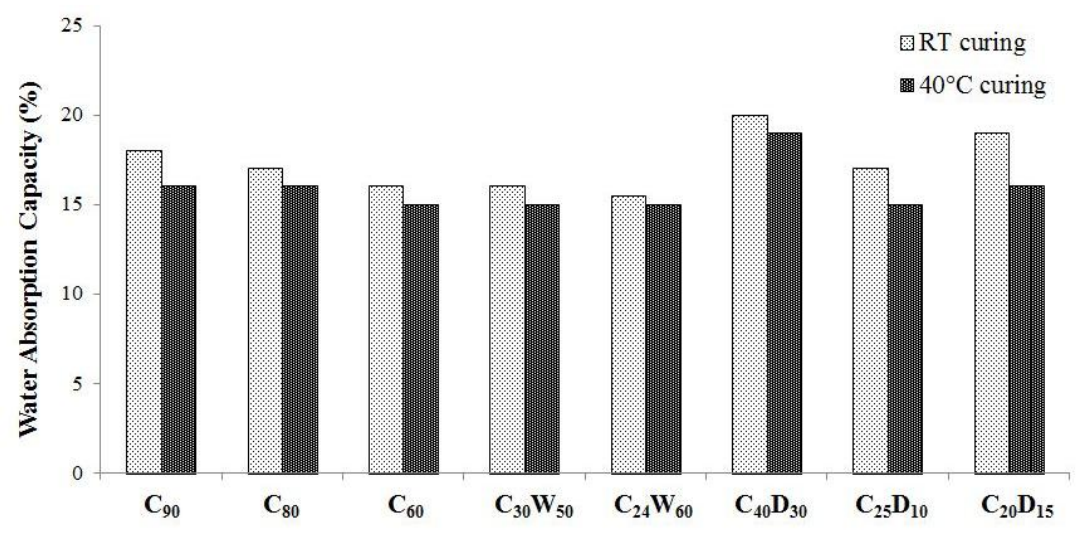

$\mathrm{C}_{30} \mathrm{~W}_{50}$ and $\mathrm{C}_{24} \mathrm{~W}_{60}$ aggregates exhibit lower strength values than $\mathrm{C}_{80}$ and $\mathrm{C}_{90}$, due to the decrease of hydration products, which hinders the development of a compact microstructure. Finally, the mixtures, $\mathrm{C}_{25} \mathrm{D}_{10}$ and $\mathrm{C}_{20} \mathrm{D}_{15}$, seem to be a reliable compromise between the two needs of recovery different wastes and obtain satisfactory mechanical properties. In order to have a commercial benchmark, a widespread, lightweight expanded clay aggregate has been considered (Leca ${ }^{\circledR}$ ). The crushing strength of this reference ranges from 0.7 to $4.5 \mathrm{MPa}$, depending on the size, so it can be 
argued that all the mixtures here presented could be suitable for many civil engineering applications where high performance isnot required.

Los Angeles coefficients of produced aggregates are shown in Figure 11. Almost all tested samples have exhibited a $L A_{40}$ fragmentation resistance class, according to table 9 of UNI EN 13242 [43]. As expected, a correlation between crushing and fragmentation resistance can be established. In fact, best mechanical performances are obtained for $\mathrm{C}_{60}$ and $\mathrm{C}_{40} \mathrm{D}_{30}$ aggregates.

Figure 10. Crushing strength of artificial aggregates.

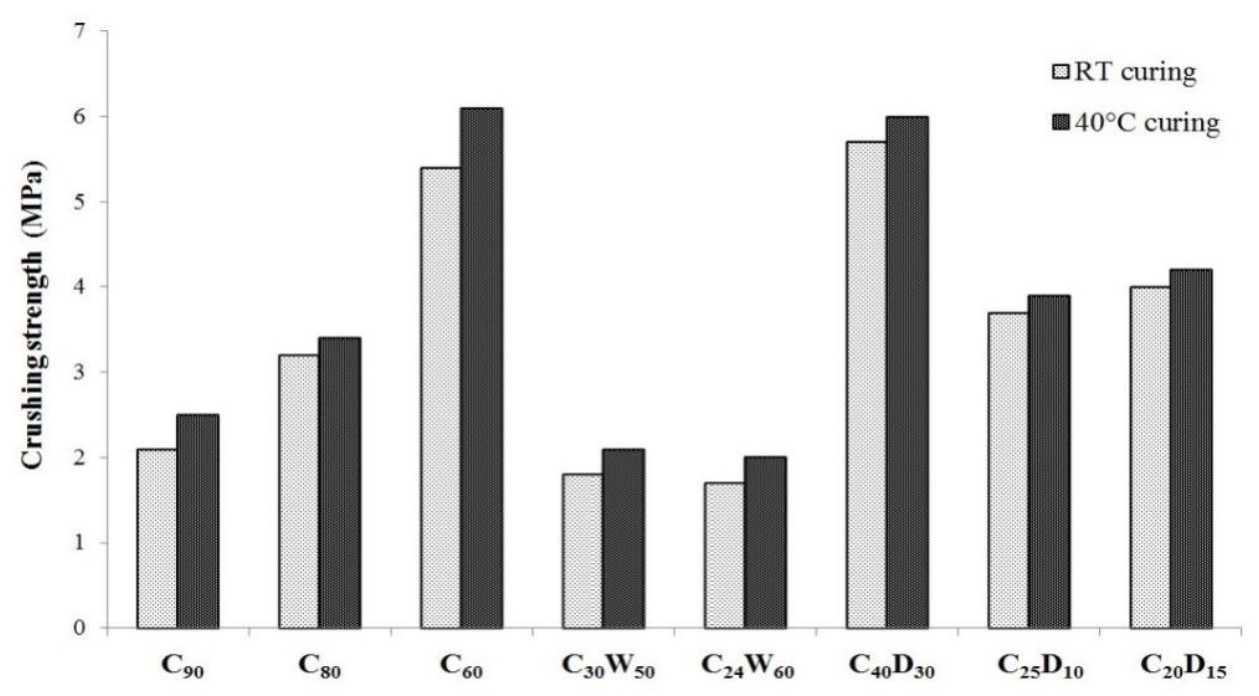

Figure 11. Los Angeles coefficient of artificial aggregates.

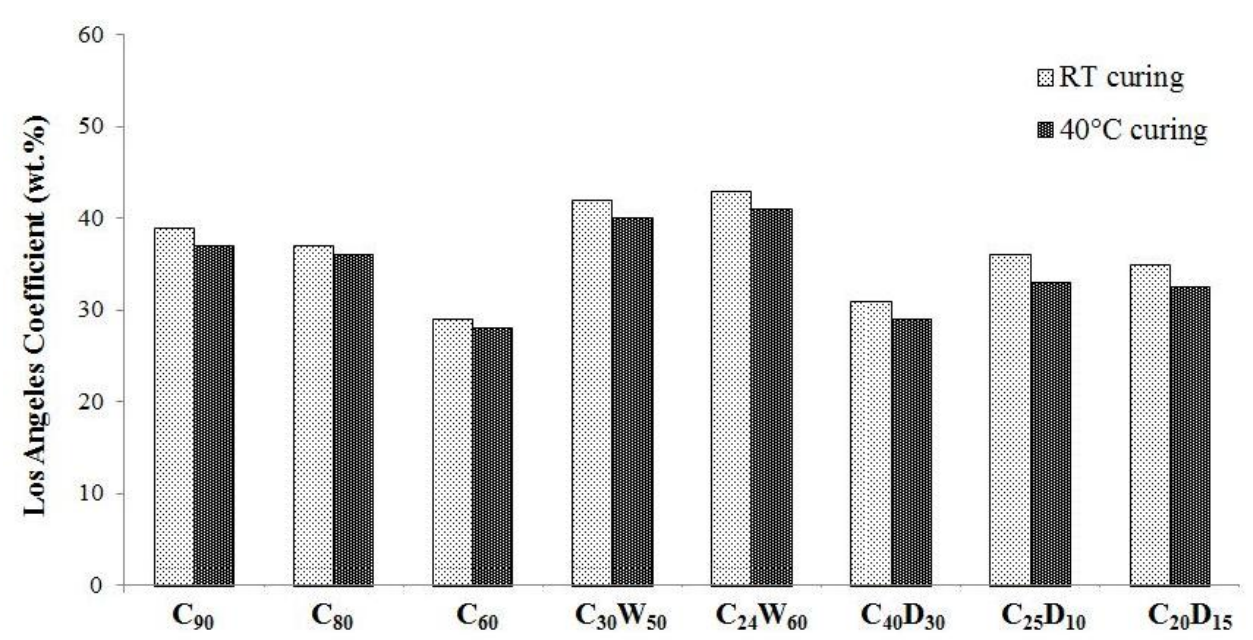

Considering all the values obtained in physico-mechanical testing of artificial aggregates, we can argue that a low temperature curing $\left(40{ }^{\circ} \mathrm{C}\right)$ can improve, even if not so relevantly, hardened products performance.

After physico-mechanical characterization, stabilization properties of designed mixtures have been also evaluated. In Table 5, heavy metals release behavior of matrices has been reported for the elements $\mathrm{Cr}, \mathrm{Cu}, \mathrm{Ni}$, and $\mathrm{Se}$. 
Table 5. Leaching behavior of the aggregates: Heavy metals release, $\mu \mathrm{g} / \mathrm{L}$.

\begin{tabular}{|c|c|c|c|c|c|c|c|c|c|c|c|c|c|}
\hline \multirow{2}{*}{\multicolumn{2}{|c|}{$\begin{array}{c}\text { Analyte } \\
\text { Renewal times, days }\end{array}$}} & \multicolumn{3}{|c|}{$\mathrm{Cr}$} & \multicolumn{3}{|c|}{$\mathbf{C u}$} & \multicolumn{3}{|c|}{$\mathbf{N i}$} & \multicolumn{3}{|c|}{ Se } \\
\hline & & 3 & 14 & 28 & 3 & 14 & 28 & 3 & 14 & 28 & 3 & 14 & 28 \\
\hline \multirow{2}{*}{$\mathrm{C}_{30} \mathrm{~W}_{50}$} & RT & 3.10 & 3.44 & 3.49 & 4.06 & 4.38 & 4.47 & 6.99 & 7.61 & 7.72 & 0.78 & 0.85 & 0.89 \\
\hline & $40{ }^{\circ} \mathrm{C}$ & 2.95 & 3.22 & 3.28 & 3.85 & 4.11 & 4.28 & 6.58 & 7.39 & 7.51 & 0.71 & 0.82 & 0.87 \\
\hline \multirow{2}{*}{$C_{24} W_{60}$} & RT & 3.26 & 3.57 & 3.65 & 4.11 & 4.43 & 4.51 & 8.59 & 8.98 & 9.13 & 0.76 & 0.87 & 0.92 \\
\hline & $40{ }^{\circ} \mathrm{C}$ & 3.09 & 3.37 & 3.52 & 3.87 & 4.09 & 4.21 & 7.63 & 8.11 & 8.25 & 0.68 & 0.81 & 0.88 \\
\hline \multirow{2}{*}{$C_{25} D_{10}$} & RT & 2.23 & 2.45 & 2.51 & 2.16 & 2.31 & 2.42 & 4.15 & 4.53 & 4.61 & 0.43 & 0.51 & 0.53 \\
\hline & $40{ }^{\circ} \mathrm{C}$ & 2.12 & 2.36 & 2.43 & 1.94 & 2.33 & 2.41 & 4.09 & 4.41 & 4.57 & 0.41 & 0.48 & 0.50 \\
\hline \multirow{2}{*}{$C_{20} D_{15}$} & RT & 2.39 & 2.73 & 2.81 & 2.09 & 2.54 & 2.62 & 4.62 & 5.17 & 5.35 & 0.49 & 0.57 & 0.61 \\
\hline & $40{ }^{\circ} \mathrm{C}$ & 2.25 & 2.61 & 2.78 & 1.87 & 2.07 & 2.15 & 4.48 & 4.87 & 4.96 & 0.47 & 0.56 & 0.62 \\
\hline
\end{tabular}

It is clear from Table 5 that $40{ }^{\circ} \mathrm{C}$ curing generally allows a better stabilization/solidification because temperature enhances hydration kinetics. Binding systems containing WFA and DDS give a better stabilization performance in comparison with $\mathrm{C}_{30} \mathrm{~W}_{50}$ and $\mathrm{C}_{24} \mathrm{~W}_{60}$. This observation can be explained by the differences in hydration products and, so, in microstructure. In fact, as will be clear in next section, $\mathrm{C}_{25} \mathrm{D}_{10}$ and $\mathrm{C}_{20} \mathrm{D}_{15}$ mixture hydration also produces ettringite, which improves the stabilizing capability of the system.

\section{Conclusions}

The main aim of this experimental program was the feasibility assessment of a sustainable process for the recycling of coal combustion solid residues, namely Weathered Fly Ash (WFA), Wastewater Treatment Sludge (WTS), and Desulfurization Device Sludge (DDS). WTS acts mostly as an inert component in binding mixtures, while DDS is able to give hydration expansive products such as ettringite. This is very important for mechanical performance and stabilizing properties of the matrices, because systems containing ettringite and $\mathrm{C}-\mathrm{S}-\mathrm{H}$ exhibit several improvements in comparison to the aggregates containing the unreactive waste, i.e., WTS. The short term (three days) results of leaching test have been evaluated in order to assess the feasibility of the recycling process here studied according to Italian regulation on simplified recovery procedure for non-hazardous wastes, revealing that this process does not pose relevant environmental issues. Physical and mechanical properties of the obtained lightweight artificial aggregates, even if compared to those of market alternatives, demonstrated to be very interesting for a productive reuse of coal combustion residues, considering that only non-weathered and non-rejected fly ash has a common recycling pathway in blended Portland cements. It can be concluded that this preliminary phase of raw waste characterization and artificial aggregates manufacturing provides good results in order to establish the suitability of the here proposed recovery process. Nevertheless, a further experimental program must be carried out. Particularly, it could be very useful to manufacture lightweight concrete panels with these artificial aggregates, analyzing durability of both aggregates and concrete. This will be the subject of future studies. 


\section{Acknowledgements}

The authors wish to express their gratitude to INAIL (Italian National Institute for Insurance against Accidents at Work and Occupational Diseases) and ENEL (National Agency for Electric Energy) for their financial and scientific support.

\section{Conflicts of Interest}

The authors declare no conflict of interest.

\section{References}

1. Bribián, I.Z.; Capilla, A.V.; Usón, A.A. Life cycle assessment of building materials: Comparative analysis of energy and environmental impacts and evaluation of the eco-efficiency improvement potential. Build. Environ. 2011, 46, 1133-1140.

2. Flatt, R.J.; Roussel, N.; Cheeseman, C.R. Concrete: An eco material that needs to be improved. J. Eur. Ceram. Soc. 2012, 32, 2787-2798.

3. Bignozzi, M.C. Sustainable cements for green buildings construction. Procedia Eng. 2011, 21, 915-921.

4. Andini, S.; Montagnaro, F.; Santoro, L.; Accardo, G.; Cioffi, R.; Colangelo, F. Mechanochemical processing of blast furnace slag for its reuse as adsorbent. Chem. Eng. Trans. 2013, 32, 2299-2304.

5. Baykal, G.; Döven, A.G. Utilization of fly ash by pelletization process; theory, application areas and research results. Resour. Conserv. Recycl. 2000, 30, 59-77.

6. Cioffi, R.; Colangelo, F.; Montagnaro, F.; Santoro, L. Manufacture of artificial aggregate using MSWI bottom ash. Waste Manag. 2011, 31, 281-288.

7. Colangelo, F.; Cioffi, R.; Lavorgna, M.; Verdolotti, L.; De Stefano, L. Treatment and recycling of asbestos-cement containing waste. J. Hazard. Mater. 2011, 195, 391-397.

8. Colangelo, F.; Cioffi, R.; Montagnaro, F.; Santoro, L. Soluble salt removal from MSWI fly ash and its stabilization for safer disposal and recovery as road basement material. Waste Manag. 2012, 32, 1179-1185.

9. Geetha, S.; Ramamurthy, K. Environmental friendly technology of cold-bonded bottom ashaggregate manufacture through chemical activation. J. Clean. Pro. 2010, 18, 1563-1569.

10. Gesoglu, M.; Güneyisi E.; Öz, H.Ö. Properties of lightweight aggregates produced with cold-bonding pelletization of fly ash and ground granulated blast furnace slag. Mater. Struct. 2012, 45, 1535-1546.

11. Limbachiya, M.C.; Leelawat, T.; Dhir, R.K. Use of recycled concrete aggregate in high-strength concrete. Mater. Struct. 2000, 33, 574-580.

12. Beretka, J.; Cioffi, R.; Marroccoli, M.; Valenti, G.L. Energy-saving cements obtained from chemical gypsum and other industrial wastes. Waste Manag. 1996, 16, 231-235.

13. Winnefeld, F.; Lothenbach, B. Hydration of calcium sulfoaluminate cements-Experimental findings and thermodynamic modeling. Cem. Concr. Res. 2010, 40, 1239-1247. 
14. Andini, S.; Cioffi, R.; Colangelo, F.; Grieco, T.; Montagnaro, F.; Santoro, L. Coal fly ash as raw material for the manufacture of geopolymer-based products. Waste Manag. 2008, 28, 416-423.

15. Cioffi, R.; Maffucci, L.; Santoro, L. Optimization of geopolymer synthesis by calcinations and polycondensation of a kaolinitic residue. Resour. Conserv. Recycl. 2003, 40, 27-38.

16. Duxson, P.; Provis, J.L.; Lukey, G.C.; Van Deventer, J.S. The role of inorganic polymer technology in the development of "green concrete". Cem. Concr. Res. 2007, 37, 1590-1597.

17. Ferone, C.; Colangelo, F.; Cioffi, R.; Montagnaro, F.; Santoro, L. Mechanical performances of weathered coal fly ash based geopolymer bricks. Procedia Eng. 2011, 21, 745-752.

18. Ferone, C.; Colangelo, F.; Cioffi, R.; Montagnaro, F.; Santoro, L. Use of reservoir clay sediments as raw materials for geopolymer binders. Adv. Appl. Ceram. 2013, 112, 184-189.

19. Ferone, C.; Colangelo, F.; Messina, F.; Santoro, L.; Cioffi, R. Recycling of pre-washed municipal solid waste incinerator fly ash in the manufacturing of low temperature setting geopolymer materials. Materials 2013, 6, 3420-3437.

20. Colangelo, F.; Roviello, G.; Ricciotti, L.; Ferone, C.; Cioffi, R. Preparation and characterization of new geopolymer-epoxy resin hybrid mortars. Materials 2013, 6, 2989-3006

21. Ferone, C.; Roviello, G.; Colangelo, F.; Cioffi, R.; Tarallo, O. Novel hybridorganic geopolymer materials. Appl. Clay Sci. 2013, 73, 42-50.

22. Ferone, C.; Colangelo, F.; Roviello, G.; Asprone, D.; Menna, C.; Balsamo, A.; Prota, A.; Cioffi, R.; Manfredi, G. Application-oriented chemical optimization of a metakaolin based geopolymer. Materials 2013, 6, 1920-1939.

23. Iucolano, F.; Liguori, B.; Caputo, D.; Colangelo, F.; Cioffi, R. Recycled plastic aggregate in mortars composition: Effect on physical and mechanical properties. Mater. Des. 2013, 52, 916-922.

24. Lancellotti, I.; Kamseu, E.; Michelazzi, M.; Barbieri, L.; Corradi, A.; Leonelli, C. Chemical stability of geopolymers containing municipal solid waste incinerator fly ash. Waste Manag. 2010, 30, 673-679.

25. Menna, C.; Asprone, D.; Ferone, C.; Colangelo, F.; Balsamo, A.; Prota, A.; Cioffi, R.; Manfredi, G. Use of geopolymers for composite external reinforcement of RC members. Compos. Part B Eng. 2012, 45, 1667-1676.

26. Van Jaarsveld, J.G.S.; Van Deventer, J.S.J.; Lorenzen, L. The potential use of geopolymeric materials to immobilise toxic metals: Part I. Theory and applications. Miner. Eng. 1997, 10, 659-669.

27. Asprone, D.; Durante, M.; Prota, A.; Manfredi, G. Potential of structural pozzolanic matrix-hemp fiber grid composites. Constr. Build. Mater. 2011, 25, 2867-2874.

28. Brandt, A.M. Fibre Reinforced Cement-Based (FRC) composites after over 40 years of development in building and civil engineering. Compos. Struct. 2008, 86, 3-9.

29. Asokan, P.; Saxena, M.; Asolekar, S.R. Coal combustion residues-Environmental implications and recycling potentials. Resour. Conserv. Recycl. 2005, 43, 239-262.

30. National Agency for Electric Energy, Environmental Report 2012. Available online: https://www.enel.com/it-IT/doc/report_2012/rapporto_ambientale_2012.pdf (accessed on 13 July 2013).

31. Qiao, X.C.; Poon, C.S.; Cheeseman, C. Use of flue gas desulphurisation (FGD) waste and rejected fly ash in waste stabilization/solidification systems. Waste Manag. 2006, 26, 141-149. 
32. Italian Standardization Organization (UNI). Tests for Geometrical Properties of Aggregates-Part 1: Determination of Particle Size Distribution-Sieving Method; UNI EN 933-1:2012; Italian Standardization Organization (UNI): Milano, Italy, 2012.

33. Italian Standardization Organization (UNI). Tests for Geometrical Properties of Aggregates-Part 2: Determination of Particle Size Distribution-Test Sieves, Nominal Size of Apertures; UNI EN 933-2:1997; Italian Standardization Organization (UNI): Milano, Italy, 1997.

34. American Society for Testing and Materials (ASTM) International. Standard Practice for Acid-Extraction of Elements from Sediments Using Closed Vessel Microwave Heating; ASTM D 5258-92 (Reapproved 1996); American Society for Testing and Materials (ASTM) International: West Conshohocken, PA, USA, 1996.

35. Italian Standardization Organization (UNI). Characterisation of Waste-Leaching-Compliance Test for Leaching of Granular Waste Materials and Sludges-Part 2: One Stage Batch Test at a Liquid to Solid Ratio of $10 \mathrm{l} / \mathrm{kg}$ for Materials with Particle Size Below $4 \mathrm{~mm}$ (without or with Size Reduction); UNI EN 12457-2:2004; Italian Standardization Organization (UNI): Milano, Italy, 2004.

36. Cioffi, R.; Marroccoli, M.; Martone, G.; Santoro, L. Utilization of zeolite-rich tuff for the manufacture of building materials based on calcium silicate and trisulphoaluminate hydrates. Thermochim. Acta 1997, 306, 93-8.

37. Italian Standardization Organization (UNI). Tests for Mechanical and Physical Properties of Aggregates - Part 6: Determination of Particle Density and Water Absorption; UNI EN 1097-6:2013; Italian Standardization Organization (UNI): Milano, Italy, 2013.

38. Italian Standardization Organization (UNI). Lightweight Aggregates-Part 1: Lightweight Aggregates for Concrete, Mortar and Grout. UNI EN 13055-1:2003; Italian Standardization Organization (UNI): Milano, Italy, 2003.

39. Saeedi, M.; Amini, H.R. Stabilization of heavy metals in wastewater treatment sludge from power plants air heater washing. Waste Manag. Res. 2009, 27, 274-280.

40. Ministro dell'Ambiente e della Tutela del Territorio. Individuazione dei Rifiuti non Pericolosi Sottoposti Alle Procedure Semplificate di Recupero (in Italian); Ministro dell'Ambiente e della Tutela del Territorio: Roma, Italy, 2006. Available online: http://www.gazzettaufficiale.biz/atti/2006 /20060115/006G0202.htm (accessed on 30 October 2013).

41. Santoro, L.; Valenti, G.; Volpicelli, G. Application of differential scanning calorimetry to the study of the system phosphogypsum-lime-aluminium hydroxide-water. Thermochim. Acta 1984, $74,35-44$.

42. Gougar, M.L.D.; Scheetz, B.E.; Roy, D.M. Ettringite and C-S-H Portland cement phases for waste ion immobilization: A review. Waste Manag. 1996, 16, 295-303.

43. Italian Standardization Organization (UNI). Aggregates for Unbound and Hydraulically Bound Materials for Use in Civil Engineering Work and Road Construction; UNI EN 13242; Italian Standardization Organization (UNI): Milano, Italy, 2003.

(C) 2013 by the authors; licensee MDPI, Basel, Switzerland. This article is an open access article distributed under the terms and conditions of the Creative Commons Attribution license (http://creativecommons.org/licenses/by/3.0/). 